\title{
Effects of Diamines (1,4-Phenylene Diamine and 4,4'-Oxydianiline) on Water Sorption Behavior of Polyimide Thin Film
}

\author{
Jongchul SEO, Anna LEE, Junseok OH, and Haksoo HAN ${ }^{\dagger}$ \\ Dept. of Chemical Engineering, Yonsei University, 134 Shinchon-Dong, \\ Seodaemun-Gu, Seoul, 120-749 Korea
}

(Received December 13, 1999)

\begin{abstract}
Several polyimide thin films based on two widely commercialized diamines, 1,4-phenylene diamine (PDA) and 4,4'-oxydianiline (ODA), were prepared from respective poly(amic acid) precursors. Water sorption behavior of the polyimide thin films was gravimetrically investigated. The water diffusion coefficient and water uptake of the PDA based polyimide thin films were in the range of $1.6 \times 10^{-10} \mathrm{~cm}^{2} \mathrm{~s}^{-1}$ to $12.6 \times 10^{-10} \mathrm{~cm}^{2} \mathrm{~s}^{-1}$ and in the range of $1.52 \mathrm{wt}$ $\%$ to $5.80 \mathrm{wt} \%$, respectively. For ODA based polyimide thin films, the water diffusion coefficient and water uptake were in the range of $3.0 \times 10^{10} \mathrm{~cm}^{2} \mathrm{~s}^{-1}$ to $14.9 \times 10^{-10} \mathrm{~cm}^{2} \mathrm{~s}^{-1}$ and in the range of $1.62 \mathrm{wt} \%$ to $2.95 \mathrm{wt} \%$, respectively. The diffusion coefficients of the polyimide thin films are closely related to in-plane orientation, crystallinity, and mean intermolecular distance, whereas water uptake is affected by packing order. PDA based polyimide thin films showed relatively higher degree of crystalline structure, small mean intermolecular distance, and high in-plane orientation than the corresponding ODA based polyimide thin films. This may have caused the lower diffusion coefficient and less water uptake in the PDA based polyimide thin films. PMDA-PDA polyimide thin film showed relatively high water uptake due to poor packing order. The effect of morphology on the water sorption behavior of the polyimide thin films was more significant and may be a critical parameter.
\end{abstract}

KEY WORDS Diffusion Coefficient / Water Uptake / Polyimides / Morphological Structure /

High temperature aromatic polyimides are used in the fabrication of microelectronic devices as inter-dielectric, alpha-particle-protecting and passivation layers, owing to relatively high thermal stability, high chemical resistance, and high mechanical toughness due to the aromatic ring and imide ring units on the chain backbone. ${ }^{1-4}$ However, despite relatively high chemical resistance characteristics, polyimides still sorb water..$^{3,5-10}$ Water sorption of polyimide films causes the reliability problems, such as displacement, package cracking, delamination, and mechanical failures in thin films. Upon uptake of water, the dielectric constants and conductivities in the polyimide films as well as the level of dielectric loss increase. Therefore, it will be very helpful to understand the water sorption behavior of polyimides and minimize the total water uptake because the final equilibrium water uptake provides an upper limit on the dielectric constant of the material. For the development of advanced materials, knowledge of environment effects on the performance of polyimide is essential for the design and selection of structural material. Consequently, many studies have been conducted on the diffusion and sorption of water in the polyimide films using various methods. ${ }^{7-9,11-14}$ Generally, the water sorption into the polyimide thin film is dependent upon the polymer morphology, which originates in the processing history and chemical structure. The degree of order in polymer molecules can generally be described as semicrystalline or amorphous. ${ }^{15-17}$ The properties of these two classes of polymers with respect to the water sorption can be expected to be very different.

However, 1,4-phenylene diamine (PDA) and 4,4'oxydianiline (ODA) have the longest history among all the commercial diamine monomers utilized in electrical and electronic applications and are widely used even today. ${ }^{2,3}$ This work characterizes the water sorption behavior of the polyimide thin films based on the widely used diamines. The water sorption and diffusion behavior of the polyimide thin films were gravimetrically investigated using a thin film diffusion analyzer. ${ }^{18-20}$ Water sorption and diffusion behavior was investigated with considering the chemical structure and the morphological structure.

\section{EXPERIMENTAL}

Poly(1,4-phenylene pyromellitamic acid) (PMDA-PDA PAA) solution was prepared under nitrogen atmosphere by slowly adding PMDA to PDA in anhydrous $N$-methylpyrrolidone (NMP) as described elsewhere. ${ }^{1-3,18-20}$ The resulting solution had a solid content of $15 \mathrm{wt} \%$. Other poly(amic acid)s were prepared in the same manner as PMDA-PDA precursor solution was synthesized: PMDAODA PAA, BPDA-PDA PAA, BPDA-ODA PAA, ODPAPDA PAA, ODPA-ODA PAA, 6 FDA-PDA PAA, and 6 FDA-ODA PAA (see Figure 1). Diamine and dianhydride monomers were purchased from commercial products (Aldrich Co. and Chriskev Co.) and purified by sublimation under reduced pressure before use.

All polyimide precursor solutions were spin coated on silicon (100) substrates. Coated wafers were prebaked at $80^{\circ} \mathrm{C}$ for $30 \mathrm{~min}$ on a hot plate under nitrogen flow. The prebaked samples were cured under flowing nitrogen by the following cure schedule: $150^{\circ} \mathrm{C} / 30 \mathrm{~min}, 230^{\circ} \mathrm{C} / 30 \mathrm{~min}$, $300^{\circ} \mathrm{C} / 30 \mathrm{~min}$, and $400^{\circ} \mathrm{C} / 60 \mathrm{~min}$. The ramping rate for each step was $2.5^{\circ} \mathrm{C} \min ^{-1}$ and cooling rate was $2.0^{\circ} \mathrm{C}$ $\mathrm{min}^{-1}$ for curing. Thickness of polyimide thin films was controlled in the range $10-15$ microns by a spin coa-

\footnotetext{
${ }^{\dagger}$ To whom correspondence should be addressed (Tel: +82-2-361-2764, Fax: +82-2-312-6401, E-mail: hshan@yonsei.ac.kr).
} 


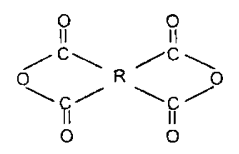
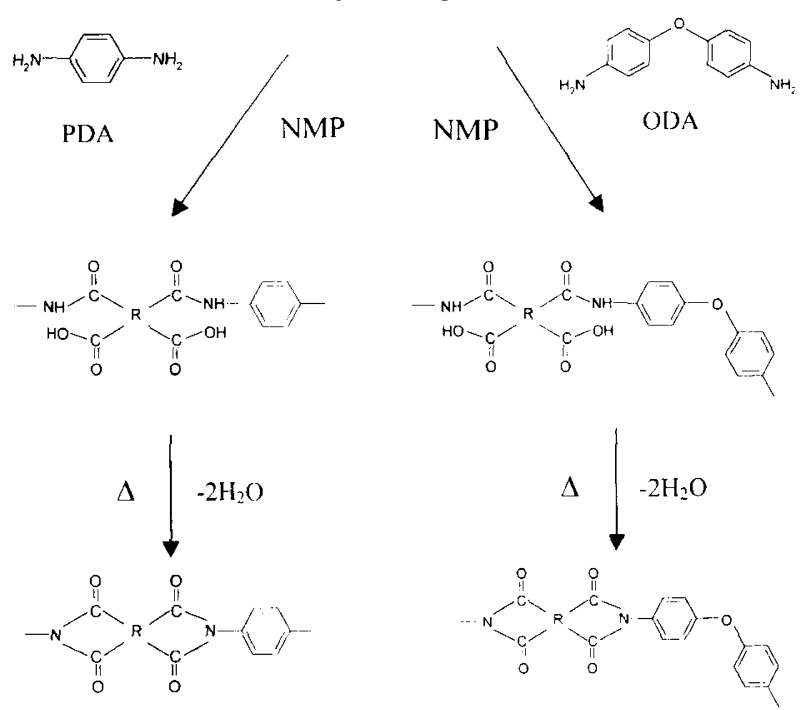

$\mathrm{R}$ :
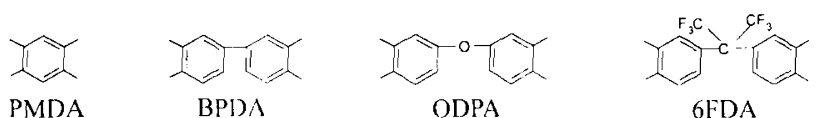

PMDA

BPI)A

ODPA

6FDA

Figure 1. Synthetic scheme of polyimides based on PDA and ODA.

tor. ${ }^{11-14}$ Film thickness was measured using a surface profiler (Tencor Instruments Co., Model P-10). Cured films were taken off from the substrates with deionized water and washed with distilled water several times and dried. The fully cured films were cut into rectangular pieces approximately $10 \mathrm{~mm} \times 15 \mathrm{~mm}$ and dried in a vacuum prior to use.

For fully cured polyimide thin films, water sorption behavior was measured at $25^{\circ} \mathrm{C}$ and $100 \%$ relative humidity $(\mathrm{RH})$ as a function of time. A thin film diffusion analyzer (Cahn Instruments Co., Model D-200) was used as described in previous studies. ${ }^{11-14,18-20}$ All sorption isotherms measured were simulated with Fick's second law, driven for an infinite slab with a constant surface concentration by Crank et al. ${ }^{21,22}$

$$
\frac{M(t)}{M(\infty)}=1-\frac{8}{\pi^{2}} \sum_{m=0}^{\infty} \frac{1}{(2 m+1)^{2}} \exp \left(\frac{-D(2 m+1)^{2} \pi^{2} t}{L^{2}}\right) \text { (1) }
$$

where $M(t)$ is water sorption at a time $t, M(\infty)$ water sorption at $t=\infty, D\left(\mathrm{~cm}^{2} \mathrm{~s}^{-1}\right)$ mutual diffusion coefficient of water and polymer systems, and $L$ film thickness. The experimental data of the entire range were fitted with eq 1 , leading to estimation of the diffusion coefficient.

Wide-angle X-ray diffraction (WAXD) patterns (transmission and reflection modes) of the polyimide thin films were obtained using a horizontal X-ray diffraction apparatus (Rigaku Co., D/Max-200 B) with nickel-filtered radiation. The $\mathrm{Cu}-K_{\alpha}$ radiation source $(\lambda=1.54 \AA)$ was operated at $35 \mathrm{kV}$ and $40 \mathrm{~mA}$ and all measurements were carried out $\theta / 2 \theta$ mode with the diffraction vector both normal to and in the plane of the films. $2 \theta$ scan data were collected in the range of $5-60^{\circ}$ at $0.02^{\circ}$ intervals with a scan speed of $0.3-0.5^{\circ} \mathrm{min}^{-1}$, depending on whether a reflection or transmission scan was made.

For molecular in-plane orientation of the polyimide thin films, the refractive index was measured using a prism coupler (Metricon Inc., Model 2010) with a He-Ne laser light of $632.8 \mathrm{~nm}$ wavelength. At this operating wavelength, as polyimide films nearly absorb light, anomalous dispersion of polyimide films can be excluded. ${ }^{4}$ All measurements were performed using a cubic zirconia prism of $n_{\mathrm{TE}}=n_{\mathrm{TM}}=2.1677$ at $\lambda=632.8 \mathrm{~nm}$. The laser light was polarized in a direction parallel to the film plane (TE mode) or perpendicular to the film plane (TM mode). In the measurement, resolution of refractive index was \pm 0.0005 . A combination of TE mode and TM mode are used for measuring the in-plane and out-ofplane refractive indices. The difference between the inplane refractive index and out-of-plane refractive index is birefringence $(\Delta)$.

\section{RESULTS AND DISCUSSION}

Polyimide thin films based on the PDA and ODA diamines were synthesized and prepared by thermal imidization at $400^{\circ} \mathrm{C}$. Water sorption behavior of the polyimide thin films was gravimetrically measured at $25^{\circ} \mathrm{C}$ and $100 \% \mathrm{RH}$ as a function of time. The water sorption isotherms of the polyimide thin films are shown in Figure 2 . The results are summarized in Table $I$. The isotherms were reasonably well fitted by Fick's second law (eq 1), regardless of morphological heterogeneity due to ordered and disordered phases in the polyimide thin films. ${ }^{11-20}$

For comparison, the isotherms of the water sorption for the PDA and ODA based polyimides are shown in Figure 2. Water sorption behavior of the polyimide thin films was quite different and strongly dependent on polyimide backbone structure. The diffusion coefficient of the PDA based polyimide films varied in the range of $1.6 \times 10^{-10} \mathrm{~cm}^{2} \mathrm{~s}^{-1}$ to $12.6 \times 10^{-10} \mathrm{~cm}^{2} \mathrm{~s}^{-1}$, in increasing order: BPDA-PDA $<$ PMDA-PDA $<$ ODPA-PDA $<6$ FDAPDA. The diffusion coefficient of the ODA based polyimide films varied in the range of $3.0 \times 10^{-10} \mathrm{~cm}^{2} \mathrm{~s}^{-1}$ to 14.9 $\times 10^{-10} \mathrm{~cm}^{2} \mathrm{~s}^{-1}$, in increasing order: BPDA-ODA $<$ PMDA-ODA $<$ ODPA-ODA $<6$ FDA-ODA. The PDA based polyimide thin film showed relatively lower diffusion coefficient than the corresponding ODA based polyimide thin film. ODA based polyimide films approached the saturated state more quickly than the corresponding PDA based polyimide films. 6 FDA-PDA and 6 FDAODA showed relatively high water diffusion coefficients.

Water absorbed in the polyimide thin films showed the same trends of the diffusion coefficients as shown in Table I. PDA based polyimide thin films show relatively lower water uptake than the corresponding ODA based polyimide thin films. However, PMDA-PDA film showed significantly higher water uptake than the corresponding PMDA-ODA film in spite of relatively low diffusion coefficient. This may indicate that there is morphological imperfectness in PMDA-PDA polyimide thin film for the water sorption due to limited chain relaxation and high glass transition temperature. ${ }^{13,18}$ The water uptake for PDA based polyimide thin films varied from $1.52 \mathrm{wt} \%$ to $5.80 \mathrm{wt} \%$, in increasing order: BPDA-PDA $<$ ODPAPDA $<6$ FDA-PDA $<$ PMDA-PDA. The water uptake for 

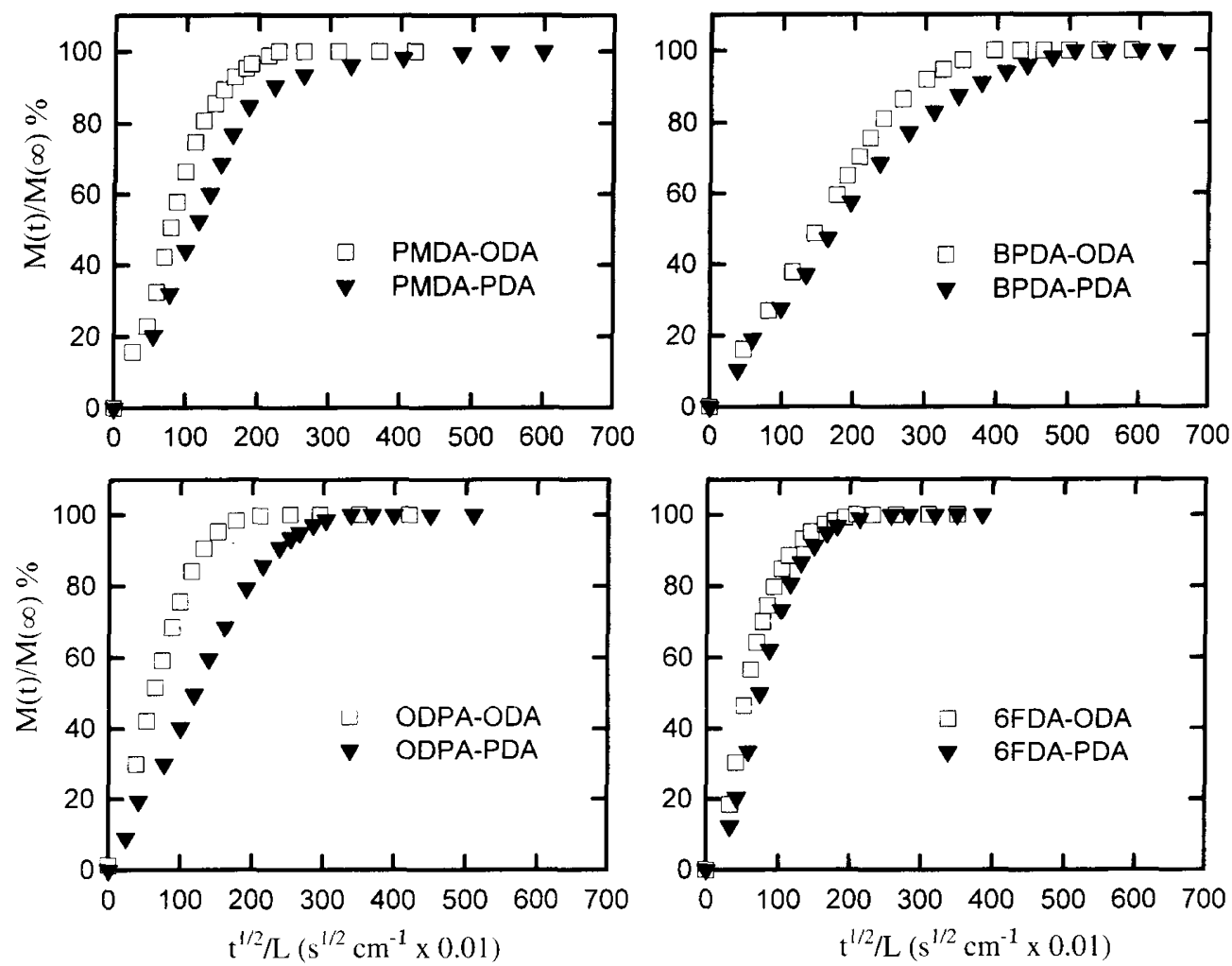

Figure 2. Isotherms of water sorption for polyimide thin films based on PDA and ODA.

Table I. Diffusion coefficients and water uptake of polyimide thin films

\begin{tabular}{|c|c|c|c|}
\hline \multirow{2}{*}{$\begin{array}{l}\text { Polyimide } \\
\text { structure }\end{array}$} & Thickness & \multirow{2}{*}{$\begin{array}{l}\text { Diffusion coefficient } \\
D \times 10^{-10} / \mathrm{cm}^{2} \mathrm{~s}^{-1}\end{array}$} & \multirow{2}{*}{$\frac{\text { Water uptake }}{\text { wt } \%}$} \\
\hline & $\mu \mathrm{m}$ & & \\
\hline PMDA-PDA & 13.50 & 3.6 & 5.80 \\
\hline PMDA-ODA & 12.12 & 9.4 & 2.95 \\
\hline BPDA-PDA & 14.08 & 1.6 & 1.52 \\
\hline BPDA-ODA & 12.80 & 3.0 & 1.62 \\
\hline ODPA-PDA & 13.02 & 4.1 & 1.72 \\
\hline ODPA-ODA & 11.20 & 12.5 & 2.89 \\
\hline 6 FDA-PDA & 13.20 & 12.6 & 2.45 \\
\hline 6 FDA-ODA & 13.36 & 14.9 & 2.90 \\
\hline
\end{tabular}

the ODA based polyimide thin films varied from $1.62 \mathrm{wt} \%$ to $2.95 \mathrm{wt} \%$, in increasing order: BPDA-ODA $<$ ODPAODA $\sim 6$ FDA-ODA $\sim$ PMDA-ODA. For the ODA based polyimide thin films, three polyimides except BPDAODA showed nearly the similar order of water uptake.

The water sorption and diffusion behavior of the polyimide thin films could be interpreted by the morphological structure and the chemical structure. ${ }^{11-14,18-20} \mathrm{By}$ comparing chemical structures of PDA diamine, ODA diamine has a ether linkage $\left(-\mathrm{O}^{-}\right)$in backbone, which can be treated as a relatively hydrophilic site for water mnolecule. ${ }^{23}$ Thus, the chemical affinity to water molecules increases in the order: PDA $\angle$ ODA. In the view of chemical affinity, one may expect that the ODA based polyimides show lower water sorption than the corresponding PDA based polyimide thin films. This is in good agreement with the water sorption of the polyimide thin films except PMDA-PDA, which showed higher water uptake in spite of relatively lower chemical affin- ity to water than the corresponding PMDA-ODA. For the dianhydride structure, chemical affinity to water increases in the order: $6 \mathrm{FDA}<\mathrm{BPDA}<\mathrm{PMDA}<$ ODPA. However, the order of chemical affinity is not in good agreement with that of the water uptake and diffusion coefficient. This may suggest that the water sorption of the polyimide thin films may be significantly affected by morphological structure; crystallinity, chain orientation, and packing order.

Generally, the degree of ordering and crystallinity in the polyimide thin films depends on the kinked group and on way samples are prepared. ${ }^{1,2}$ In comparison of PDA diamine structure, ODA diamine in the polyimide has a kinked ether linkage unit per repeating chain unit (see Figure 1). The ODA based polyimide thin films may have relatively amorphous and less ordered structure than the corresponding PDA based polyimide thin films. ${ }^{1,11,18}$ In this study, all polyimide samples were prepared from the same curing and thickness range. Thus, the morphological structure of the polyimide films may be solely dependent on chemical structure. ${ }^{11-14}$

For morphological structures of fully imidized polyimide thin films, WAXD (transmission and reflection modes) and refractive index measurements were performed. For WAXD measurement, the transmission pattern gives a structural information for the film plane, whereas the reflection pattern does a structural information for the out-of-film plane. ${ }^{11-14,24}$ Transmission and reflection WAXD results are shown in Figures 3 and 4 , respectively.

Except for 6 FDA-PDA, all PDA based polyimide thin films showed $(00 l)$ diffraction peaks in the transmission pattern corresponding to the molecular order along the chain axis. In contrast, $(00 l)$ diffraction peaks in the 

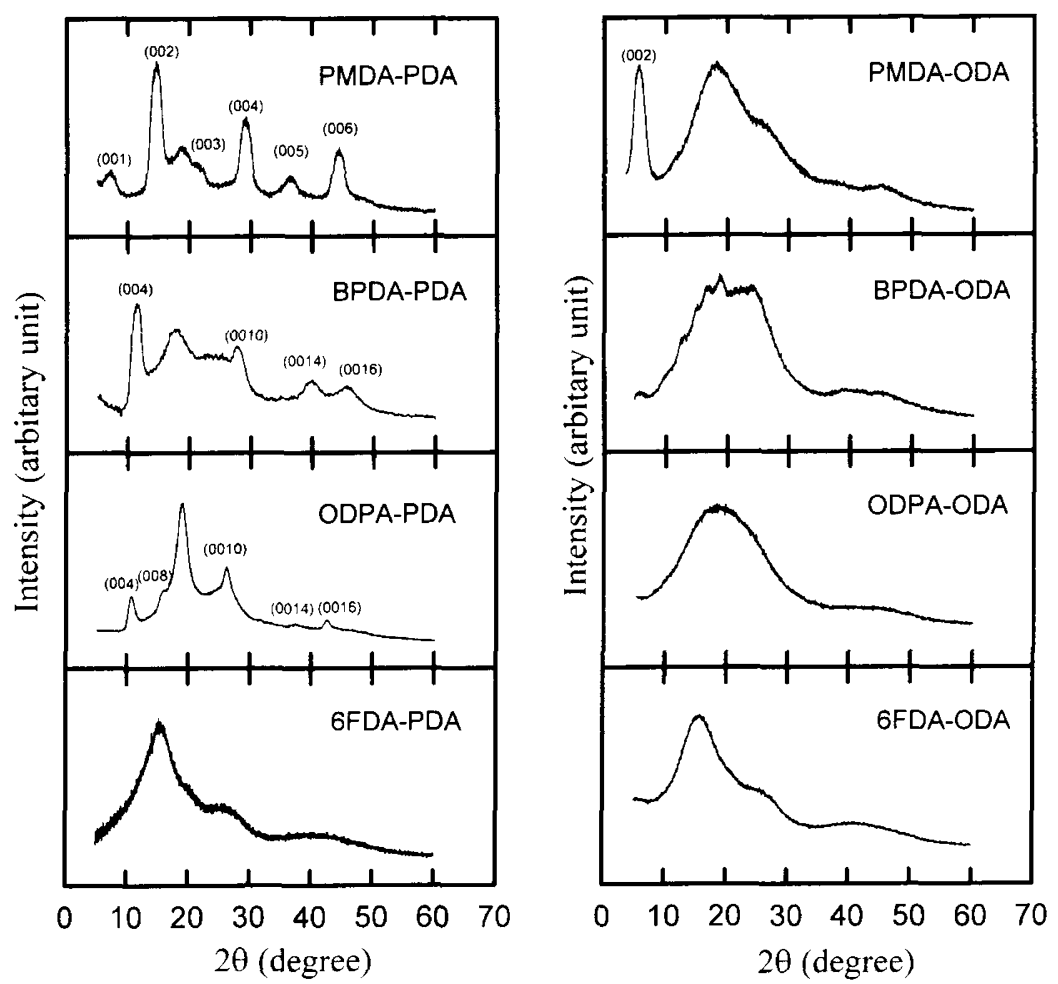

Figure 3. Transmission WAXD patterns of polyimide thin films based on PDA and ODA.
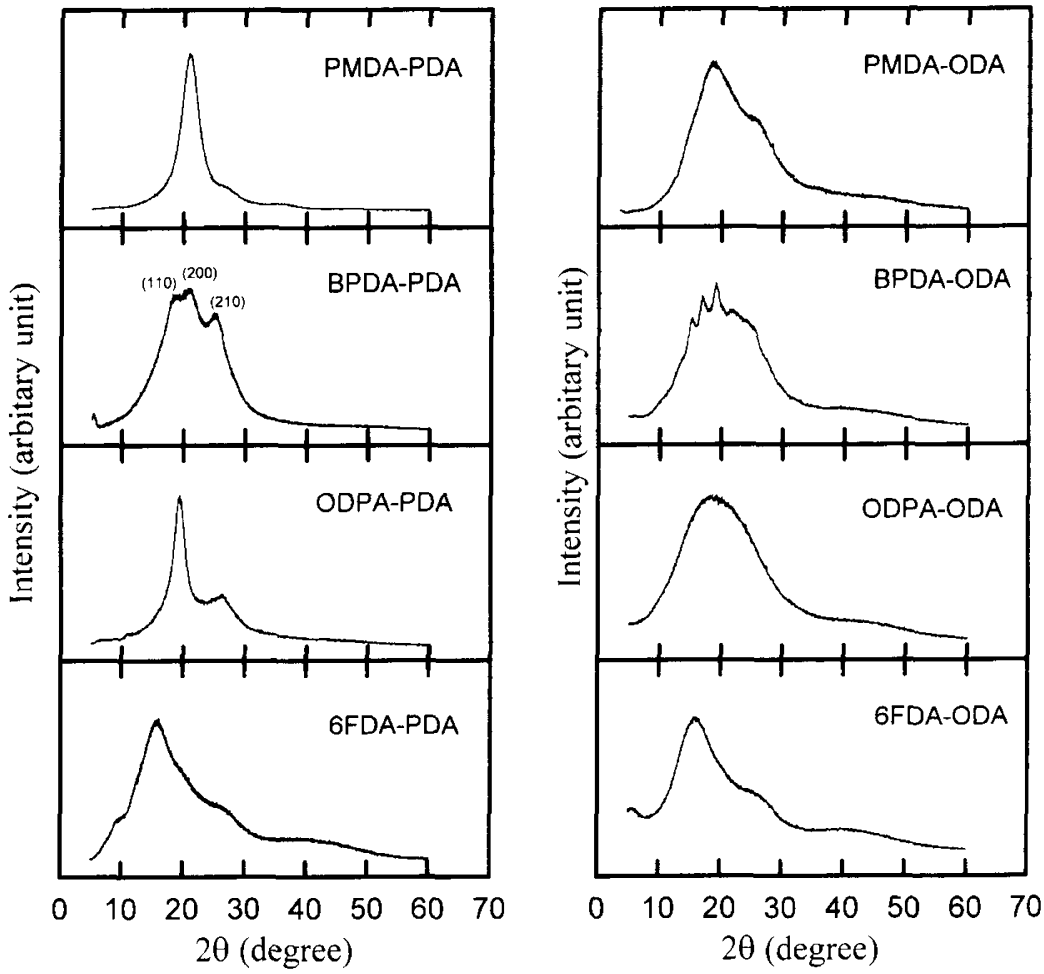

Figure 4. Reflection WAXD patterns of polyimide thin films based on PDA and ODA.

transmission patterns were not apparent for ODA based polyimide thin films. PMDA-ODA showed only one sharp (002) diffraction peak at a low angle of $2 \theta=5.74^{\circ}$ and BPDA-ODA showed multiple diffraction peaks on the big amorphous halo peak in the diffraction patterns over the angle range of 10 to $30^{\circ}$. This indicates that the PDA based polyimide film has higher degree of crystal- linity than the corresponding ODA based polyimide film. The mean intermolecular distance in the polyimide films, ${ }^{18-20,24}$ which may be a critical factor of water sorption, was calculated from the characteristic transmission peaks as shown in Table II. The mean intermolecular distance for the PDA based polyimide thin films varied in the range of 4.78 to $5.65 \AA$ and those for the ODA 
based polyimide thin films varied in the range of 4.89 to $5.66 \AA$, respectively. The mean intermolecular distance was relatively higher in the ODA based polyimide thin films than in the PDA based polyimide thin films, indicating that polymer chains of the PDA based polyimide thin films are more or less well oriented in film plane. PDA based polyimide thin films had relatively higher crystalline structures and in-plane orientation than the corresponding ODA based polyimide thin films. PDA based polyimide thin films having more ordered structures thus showed lower diffusion coefficients than the corresponding ODA based polyimide thin films, in good agreement with the diffusion behavior of the polyimide thin films.

The reflection patterns of polyimide thin films are quite different from the transmission patterns as shown in Figure 4. Reflection WAXD patterns of the polyimide thin films except BPDA-PDA, ODPA-PDA, and BPDAODA, exhibited only one amorphous halo peak. This may indicate that other polyimides, PMDA-PDA, PMDAODA, ODPA-ODA, 6 FDA-PDA, and 6 FDA-ODA, have poor packing order. In spite of high in-plane orientation and small mean intermolecular distance, PMDA-PDA showed poor packing order, which may be closely related to the glass transition temperature $\left(T_{\mathrm{g}}\right)$. Due to the high $T_{\mathrm{g}}\left(>500^{\circ} \mathrm{C}\right)$ of PMDA-PDA over the final temperature of curing, ${ }^{2,3}$ there might be very limited chain mobility and poor possibility to rearrange itself. This may cause ir-

Table II. Mean intermolecular distances of polyimide thin films based on PDA and ODA

\begin{tabular}{|c|c|c|}
\hline \multirow{2}{*}{$\begin{array}{l}\text { Polyimide } \\
\text { structure }\end{array}$} & Thickness & \multirow{2}{*}{$\begin{array}{c}\text { Mean intermolecular } \\
\text { distance }^{\text {a }}\end{array}$} \\
\hline & $\mu \mathrm{m}$ & \\
\hline PMDA-PDA & 13.50 & $4.78 \AA\left(18.8^{\circ}\right)$ \\
\hline PMDA-ODA & 11.97 & $4.94 \AA\left(18.2^{\circ}\right)$ \\
\hline BPDA-PDA & 14.08 & $4.87 \AA\left(18.5^{\circ}\right)$ \\
\hline BPDA-ODA & 12.80 & $4.90 \AA\left(18.1^{\circ}\right)$ \\
\hline$\overline{O D P A}-\overline{P D A}$ & 13.02 & $4.78 \AA\left(18.8^{\circ}\right)$ \\
\hline ODPA-ODA & 11.20 & $4.89 \AA\left(18.4^{\circ}\right)$ \\
\hline 6 FDA-PDA & 13.20 & $5.65 \AA\left(15.9^{\circ}\right)$ \\
\hline 6 FDA-ODA & 13.36 & $5.66 \AA \hat{\AA}\left(15.8^{\circ}\right)$ \\
\hline
\end{tabular}

${ }^{a}$ Calculated from peak maximum of amorphous halo in the transmission WAXD pattern. regular packing of polymer chains and morphological imperfectness for water sorption. ${ }^{1,8,11,18-20}$ However, BPDA-PDA showed three $(h k l)$ peaks in the reflection pattern, such as (110), (200), and (210) and ODPA-PDA showed the additional shoulder diffraction peaks around 9.5-10.5 and 25.5-26.5 . BPDA-ODA showed multiple diffraction peaks on the big amorphous halo peak in diffraction patterns over the angle range of 10 to $30^{\circ}$ $(2 \theta)$. These reflection WAXD patterns may indicate that packing order in films is relatively higher in the BPDAPDA and ODPA-PDA polyimides than in the corresponding BPDA-ODA and ODPA-ODA polyimides. For ODA based polyimides, three polyimides except BPDA-ODA showed only amorphous halo, which may indicate irregular packing of polymer chains. This is well consistent with the results of water uptake in the polyimide thin films.

The molecular in-plane orientation of the polyimide thin films was measured using the prism coupler. As shown in Table III, all polyimide thin films showed larger in-plane refractive index $\left(n_{\mathrm{xy}}\right)$ than out-of-plane refractive index $\left(n_{z}\right)$, regardless of chemical structure. This indicates that the polyimide thin films had positive birefringence $(\Delta)$ and the polymer chains are preferentially aligned in the film plane. In comparison, $n_{\mathrm{xy}}$ and the average refractive index $\left(n_{\mathrm{av}}\right)$, indicating the inplane orientations of polymer films increases in the order, BPDA-PDA > PMDA-PDA > ODPA-PDA > 6 FDAPDA for the PDA based polyimide thin films and BPDAODA > PMDA-ODA > ODPA-ODA > 6 FDA-ODA for ODA based polyimide thin films, respectively. PDA based polyimide films showed relatively higher $n_{\mathrm{xy}}$ and $n_{\mathrm{av}}$ than the corresponding ODA based polyimide films, which indicates that the PDA based polyimide films are preferentially aligned in the film plane. These results are well consistent with the WAXD results and diffusion behavior of the polyimide thin films.

Water sorption behavior is closely related to the morphological structure and chemical structure. PDA based polyimides had relatively well-developed morphological structure (i.e., higher in-plane orientation and higher degree of crystalline structure) and lower chemical affinity than the corresponding ODA based polyimides. This may cause lower diffusion coefficient and less water uptake in the PDA based polyimide thin films than the cor-

Table III. Refractive indices and birefringences of polyimide thin films based on PDA and ODA

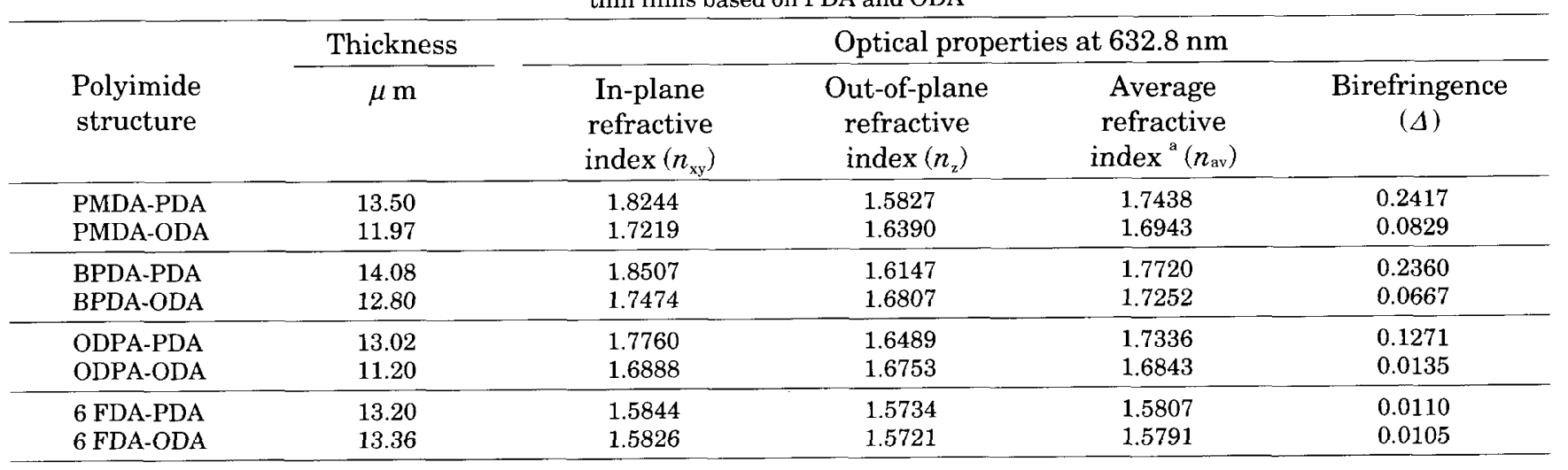

${ }^{\mathrm{a}} n_{\mathrm{av}}=\left(2 n_{\mathrm{xy}}+n_{\mathrm{z}}\right) / 3$ 
responding ODA based polyimide thin films. PMDAPDA showed relatively high water uptake due to lower packing order. However, BPDA-PDA and BPDA-ODA showed good packing order, high orientation, and high crystalline structure. This may cause relatively low diffusion coefficients and water uptake of BPDA-PDA and BPDA-ODA polyimide thin films. However, 6 FDA-PDA and 6 FDA-ODA had bulky di(trifluoromethyl) groups in main chain, inducing amorphous structures and irregular chain ordering due to weak molecular interaction and steric hindrance. This is in good agreement with morphological structure investigated by WAXD and refractive index measurements and well applicable to relatively high diffusion coefficients in the 6 FDA based polyimide thin films. ${ }^{4,8,19,25}$

\section{CONCLUSIONS}

The water sorption behavior of the ODA and PDA based polyimide thin films was gravimetrically investigated. The water sorption behavior of polyimides was quite different depending on the polyimide. Water diffusion coefficient of the PDA based polyimide films varied in the range of $1.6 \times 10^{-10} \mathrm{~cm}^{2} \mathrm{~s}^{-1}$ to $12.6 \times 10^{-10} \mathrm{~cm}^{2} \mathrm{~s}^{-1}$, in increasing order: BPDA-PDA < PMDA-PDA < ODPA-PDA $<6$ FDA-PDA. The water uptake varied from $1.52 \mathrm{wt} \%$ to $5.80 \mathrm{wt} \%$, in increasing order: BPDAPDA $<$ ODPA-PDA $<6$ FDA-PDA $<$ PMDA-PDA. The diffusion coefficients of the ODA based polyimide films varied in the range of $3.0 \times 10^{-10} \mathrm{~cm}^{2} \mathrm{~s}^{-1}$ to $14.9 \times 10^{-10}$ $\mathrm{cm}^{2} \mathrm{~s}^{-1}$, in increasing order: BPDA-ODA $<$ PMDA-ODA $<$ ODPA-ODA $<6$ FDA-ODA. The water uptake varies from $1.62 \mathrm{wt} \%$ to $2.95 \mathrm{wt} \%$, and is in the increasing order: BPDA-ODA < ODPA-ODA 6 FDA-ODA PMDA-ODA. In comparison of ODA based polyimide thin films, PDA based polyimide thin films showed relatively well-developed morphological structures, including higher in-plane orientation, higher degree of crystalline structure, and small mean intermolecular distance. The well-developed morphological structures of PDA based polyimide thin films lead to relatively lower diffusion coefficients and lower water uptake than the corresponding ODA based polyimide thin films. PMDA-PDA polyimide thin film showed relatively high water uptake due to poor packing order. The effects of morphological structure in the polyimide thin films were more significant and may be a critical parameter for water sorption behavior. The diffusion coefficients of polyimide thin films are closely related to in-plane orientation and mean intermolecular distance, whereas water uptake is affected by packing order.

Acknowledgment. We thank the Korea Research Foundation (KRF) (Contract No. 1998-001-E 01258) for financial support.

\section{REFERENCES}

1. M. I. Bessonov and V. A. Zubkov, "Polyamic Acids and Polyimides; Synthesis, Transformations, and Structure", CRC Press, Boca Raton, FL, 1993.

2. M. K. Ghosh and K. L. Mittal, "Polyimides; Fundamentals and Applications”, Marcel Dekker, New York, N.Y., 1996.

3. K. L. Mittal, "Polyimide; Synthesis, Characterization, and Applications”, Plenum Press, New York, N.Y., 1984.

4. C. Feger, M. M. Khojaseh, and M. S. Htoo, "Advances in Polyimide Science and Technology", Technomic Publish., Lancaster, 1993.

5. F. Bellucci, I. Khamis, S. D. Senturia, and R. M. Latanision, $J$ Electrochem. Soc., 137, 1778 (1990).

6. J. Melcher, Y. Daben, and G. Arlt, IEEE Trans, Elect. Ins., 24, 31 (1989).

7. D. D. Denton, D. R. Day, D. F. Priore, and S. D. Senturis, J. Electr. Mater., 14, 119 (1985).

8. K. I. Okamoto, N. Tanihara, H. Watanabe, H. Tanaka, H. Kita, A. Nakamura, Y. Kusuki, and K. Nakagawa, J. Polym. Sci., Polym. Phys., 30, 1223 (1990).

9. D. K. Yang, W. T. Koros, H. B. Hopfenberg, and W. T. Stannett. J. Appl. Polym. Sci., 31, 1619 (1985).

10. L. R. Iler, C. Laundon, and W. J. Koros, J. Appl. Polym. Sci., 27, 1163 (1982).

11. M. Ree, H. Han, and C. C. Gryte, High Perform. Polym., 6, 621 (1994).

12. H. Han, C. C. Gryte, and M. Ree, Polymer, 36, 1663 (1995).

13. H. Han, J. Seo, M. Ree, S. M. Pyo, and C. C. Gryte, Polymer, 39, 2963 (1998).

14. M. Ree, H. Han, and C. C. Gryte, J. Polym. Sci., Polym. Phys., 33, 505 (1995).

15. H. Isoda, H. Shimada, M. Kochi, and H. Kambe, J. Polym. Sci., Polym. Phys., 19, 1293 (1981).

16. T. P. Russell, Polym. Eng. Sci., 24, 345 (1984).

17. T. P. Russell, J. Polym. Sci., Polym. Phys., 22, 1105 (1984).

18. J. Seo, H. Han, S. Kim, H. Chung H, and J. I. Joe, Polym. J., 31, 127 (1999).

19. J. Seo, H. Han, A. Lee, and J. Han, Polym. J., 31, 342 (1999).

20. J. Seo, A. Lee, C. Lee, and H. Han, J. Appl. Polym. Sci., 76, $1315(2000)$

21. J. Crank, "The Mathematics of Diffusion", Clarendon Press, Oxford, 1976.

22. J. Crank and G. S. Park, "Diffusion in Polymers", Academic Press, London, 1968.

23. D. W. van Krevelen, "Properties of Polymers", 3rd ed, Elsevier Science, Amsterdam, 1990.

24. B. D. Cullity, "Elements of X-ray Diffraction", 2nd ed, Addison-Wesley, London, 1977.

25. H. Tsuzumi, K. Toi, T. Ito, and T. Kasai, J. Appl. Polym. Sci., 64, 389, (1997). 